\title{
Come and See the Poor People: The Pursuit of Exotica
}

\author{
M i c h a e I W o o I f \\ The Foundation for International Education, London
}

\section{Seduced by the Exotic}

\section{Introduction}

The call to expand opportunities for study abroad students in "non-traditional" locations has become a kind of mantra throughout the international education community. This call is almost always allied to the intent significantly to expand numbers going to these non-traditional locations. Of the three key objectives in the Lincoln Commission report, the second is that "efforts be made to expand the number of American students studying in non-traditional countries." ${ }^{1}$ To a degree, this notion has become the new orthodoxy and there is a widespread commitment towards these perceived ideal objectives.

My concern with this vision is that it is neither entirely realistic nor wholly desirable. It is built out of a misplaced and sometimes condescending enthusiasm for regions and nations constructed through US lenses as an "exotic" other. The whole becomes even more complex and suspect when, as is often the case, the non-traditional locations become melded with the developing world. The Lincoln Commission melds the two when it envisages "an expansion of study abroad programs, especially in developing countries." ${ }^{2}$ The National Security Education Program articulates similar objectives in supporting students who pursue overseas education in " the languages and cultures of world regions that are less-frequently studied." ${ }^{3}$ The purpose of this essay is to define some of the issues that permeate this area and to suggest that the field of education abroad needs to take a more concentrated view of what it means and intends.

\section{The Language of Tourism}

There are many problems associated with the objective of "non-traditionalism" and one of particular concern is that it defines study aboard too readily in the language of tourism. There are a wearying number of possible examples: "Trek the ancient tropics," "When you tire of techno, have a quiet drink with Taoist monks," "Far away and exotic lands of Africa, South East Asia, Australia and 
Oceania," "Rainforest adventure." ${ }^{4}$ These are examples drawn from program providers. If student evaluations are reviewed it is clear that the experiences are seen predominantly as a means of exploring an "exotic" location for purposes that demote the academic content to a secondary status. The equation of nontraditional with developing too often signifies that the demand is based on the travel agent's attraction to the exotic allied with a quasi-missionary zeal to engage with poverty. This is also apparent in student comments where rarely is there an attempt to get beyond the first-person. The host location exists as a space through which students travel with the objective of expanding their perceptions. While this is not a bad or demeaning objective, there is rarely a sense of serious exploration beyond the self.

An emphasis on the non-traditional in this context weakens the case for the centrality of study abroad as a means of enhancing learning, undermines the inherent seriousness of international education and does a disservice to serious study objectives that can, and are, pursued in non-traditional locations. This constructs study abroad as potentially a form of educational tourism, "a trip," motivated, at worst, by a kind of voyeurism in which privileged young Americans go to observe relative poverty in a developing country.

There are, of course, many valid reasons to expand study abroad in nontraditional locations. A significant expansion of minority language study would lead, rationally and reasonably to the expansion of study abroad in relevant locations. Has that expansion taken place? Is there a marked growth in African Studies in the USA that would stimulate the need to develop more programs? The evidence is otherwise. In the academic year 1992-1993, 41 bachelor's degrees were awarded in African Studies. In 2002-2003, the figure had fallen to 33. Between 1998-2002, the number of degrees awarded reflects a $2 \%$ growth. The picture in other area studies shows, similarly, very minor expansion, if any, in relevant area studies. ${ }^{5}$

In short, if there were a more credible rationale beyond "exoticism" it would be reflected in a growth of domestic programs relevant to non-traditional programs, e.g. Asian languages, African Studies, African languages, etc. The reality is different:

Approximately ninety-one percent of Americans who study foreign languages in our schools, colleges, and universities choose French, German, Italian, or Spanish; while only nine percent choose languages such as Arabic, Chinese, Japanese, Yoruba, Russian, Swahili and the other languages spoken by the overwhelming majority of people around the world. 
While many of the less commonly taught languages are critically important to our national interest in the 21 st century, the low level of current enrollments jeopardizes the very existence of the relatively few existing programs, and significantly restricts access to language learning opportunities for the large majority of students in the United States. ${ }^{6}$

It is apparent that there has been no perceptible explosion in the demand for minority language study on US campuses that might create an academic justification for a major expansion of programs in non-traditional locations. Undergraduate enrolments in Twi, for example, reached the total of 75 in 2002, which hardly suggests that there is a linguistic rationale for many new programs in Ghana. Enrolments in Swahili also indicate a very modest growth from 1,199 in 1998 to 1,483 in 2002. ${ }^{7}$ It is clear that the call for the expansion of programs in non-traditional programs is not being driven by an academic agenda.

The demand for growth in these areas and regions has been stimulated by a combination of the notion of the exotic as an attraction in itself with the missionary-like sense that, somehow or another, an American presence is an added value in developing countries. This is study abroad being constructed somewhere between the travel agency and the Mission.

Furthermore, what does this new emphasis imply to students who, with probably more academic rationale, choose to study in Western Europe? It implicitly sends a signal that their experiences are, to some degree, less valid, less "exciting." What that does, in essence, is define the validity of experience by location. The emphasis is on place not on what is studied there; the significance of the academic rationale is minimized in the seductive images of exotica. As has been noted, there is no significant growth in serious study of non-traditional locations and languages on US campuses. The call for program growth in nontraditional locations is not based on solid academic grounds but on a shallow pursuit of the new.

\section{The National Security Argument}

The other rationale frequently cited for non-traditionalism is that it is the USA's political interest to learn more about "world regions that are critical to US national security" ${ }^{8}$ or, as the Lincoln Commission argues, "study abroad is simply essential to the nation's security." There certainly is a strong political case for this argument. Study abroad is a significant mechanism for breaking down national insularity but the argument also has two consequences: 
a) It frames an educational policy in terms only of US political interest. Rather than focus on the mutual benefits that accrue from contact between young people of different cultures, the argument frames itself in terms only of a single political perspective. This may be a valid tactic to extract funding from reluctant governments but it is not the language of true educational discourse. International education needs to construct itself in terms of the benefits that accrue from exchange and interaction between participants from across the world. It should not be seen as a tool of a single national interest.

b) It minimizes the educational aspect of study abroad in favor of the political. It also places an emphasis that does a disservice to the field where the argument is that education abroad enhances learning. If education abroad is to retain credibility it has to be seen to be adding value to educational experience at home.

\section{Who Wants to Go?}

A further significant matter is the question of student demand. The call for a large increase in study in non-traditional locations is unrealistic on a number of fronts. There are questions of resources in potential host communities, and the impact on those communities. But the unanswerable fact is that there is no huge demand from the market for a radical increase in programs in many of those locations. In India, for example, programs are hardly over-subscribed. The number of students going to India in 2002-3 increased by $65 \%$ to 1,157 , but that remains a very small number compared to over 32,000 students who study in the United Kingdom, over 20,000 who choose to go to Spain, over 13,500 who go to France. The percentage of study abroad students going to Africa increased very modestly from $2.8 \%$ of the total in $2002-3$ to $3 \%$ in $2003-4 .{ }^{10}$ The reality, however unpalatable this might be, is that student demand remains predominantly for programs in Western Europe.

In this context students know more than their advisers and choose more wisely based, arguably, on what makes most academic sense and what relates most to the home curriculum of US universities. The demand for growth of programs in non-traditional locations is not student led, nor does it reflect an increasing demand for genuine intellectual exploration. It is led by some of the leadership in the field who have lost sight of academic credibility and student interest in their thoughtless pursuit of the new. 


\section{The I mpact of Study A b r a d o n Host Communities: African Examples}

We need to develop programs that enhance trans-cultural understanding not only for our American students, but also for the members of the host communities in which we operate... Where the social, economic, cultural and educational differences are great between communities, as is often the case when America meets Africa, then the potential for misunderstanding and mutually detrimental consequences is at its greatest. ${ }^{11}$

Christine Hudson

\section{Resource Implications}

The objective of non-traditional expansion without establishing academic credibility has been, I have argued, misplaced and unrealistic. It has also been unaware of the reality of the demands that a substantial increase in US study abroad would make upon those communities. The existence (or otherwise) of a sufficient infrastructure is an obvious factor. US study abroad students are highly demanding of both human and physical resources and, in a limited resource environment, the local students may well feel resentful at the diversion of those towards one national group.

In my own experience at The University of Cape Town, the international office struggled with the reality that there were, in practice, two groups of international students. By far the largest came from within Africa. As one of the leading institutions in sub-Saharan Africa, the University of Cape Town attracted students from across the continent. There was also a substantial group of US study abroad students. The US students had paid for, and expected, a level of student service way beyond that offered to the other international students on campus (let alone the national students). While this reality was not always a source of tension, it did establish a communication barrier and the situation contained within itself real potential for resentment and ill feeling. As Hudson signifies, we need to avoid turning non-traditional locations into sites where we achieve the very opposite of the mutual understanding we intend:

What we do not want to do is make the already large divide between Africa and America greater. American wealth and dominance should not be flaunted at local communities. The consumerist attitude that we paid for a service and thus demand it (according to American standards), needs to be suspended for a while; especially when we know that we 
would have to pay considerably more for that service if we were back in the USA. Students and staff of study abroad programs should remember that the opportunity to spend time in another's country is a privilege to experience and not a right. ${ }^{12}$

If we do seriously intend to develop more programs for more students in non-traditional locations, the resource implication has to be grasped directly and funds directed from US university sources truly to support the infrastructure of host universities. The demands of the study abroad minority may be more than the host universities can, and should, bear. The enthusiasm of the Lincoln Commission for developments in non-traditional locations should have led to a proposal to help build infrastructure in key locations that would enable the study abroad students to benefit and that would have further given local students access to improved resources. Instead the Lincoln Commission proposed the following fund allocation:

Of the funds available for the program, 25 per cent should be allocated to the national direct grants program, with the rest allocated to institutions and consortia. The institutional/consortia side of the program should include a requirement that not less than 85 per cent of the Lincoln fund be made available for student award. ${ }^{13}$

In short, the proposal is to stimulate growth through funding without giving host institutions the resources to meet that enhanced demand. ${ }^{14}$

\section{Academic Implications}

It is apparent that non-traditionalism has not fully considered the impact of diverse teaching and learning styles on host universities in many parts of the world. Our enthusiasm for study abroad sometimes leads us to enlist in myths of globalization and we thus generate expectations of unhampered student mobility. The problems inherent in this context can be illustrated by reference to two theoretical models at either end of a spectrum of possibility. For the sake of shorthand they may be called the "liberal" and the "theological" model. It should be stressed that these are not specific institutions but extreme versions of certain characteristics that may be found within universities and schools in different national contexts.

The objectives and characteristics of a liberal school or university might be as follows: The curriculum demonstrates cultural diversity and the non-unitary notion of culture or history. This mythical place has a function in debates about what constitutes national culture and identity. It frequently creates conflicting notions of history (as in USA — Black, Gay, Native American, Women's 
Studies) and oppositional versions of culture. The faculty express and encourage skepticism and inculcate values that permit disassociation from establishment values. Paradoxically, the State pays these faculty to perform (and perhaps, thus, to contain) this function.

At the other end of this imaginary spectrum is the theological model. The term is broadly metaphorical. It signifies an institution that exists predominantly to enforce a given orthodoxy. It functions to some degree as a guardian of traditional values be they religious, political, moral or whatever. The primary objective of this equally mythical place is to transmit "truth" not to challenge the notion of truth itself. In practice most educational systems and the institutions in them do not conform to these extreme models but exist somewhere between.

A potential pitfall in terms of student mobility is the assumption that educational systems fundamentally cohere. This fails, among other things, to recognize the variations shaped by liberal or theological tendencies. Failure to recognize difference or the bland assumption of shared purpose may lead to frustration and alienation unless understood and planned for within the development of international educational relations. The recognition of these diverse patterns is a pre-requisite for the creation of effective mechanisms for student mobility.

At a grassroots level, the impact may be manifest in conflicting notions of what constitutes acceptable classroom behavior. American students, for example, may come to a host university overseas with an expectation that the objective of the class is to create a field of debate in which opinions are proposed and challenged. In some cultures, this expectation leads to behavior that is both intimidating to other students within the class, and inappropriate to the teaching faculty. The reverse experience is, incidentally, also common: students who come to the US or the UK with the expectation that the professor is the source of unchallenged wisdom and the gatekeeper of cultural knowledge have difficult times in classes where the professor, instead of being the keeper of the holy grail of learning, performs the role of devil's advocate or, indeed, agitator.

These are, of course, not absolutes but models at the end of a theoretical spectrum. That said, it is clear that US students are shaped by experiences in a liberal model whereas the mode of teaching and learning in most African contexts is closer to the theological mode.

One impact of study abroad on a host campus may, therefore, be to disrupt or destabilize the classroom when a predominantly liberal learning mode is brought in an unmediated way into a predominantly theological teaching situation. At worst, the US student in these circumstances can appear to be 
enacting the stereotype of the loud, ugly American. Economic benefits to the host university should be seen in the context of cultural cost.

Thus, while an increase in US study abroad programs in the developing world will probably bring some (unreliable) economic benefits; it will also have an impact on the local students that will be much more ambiguous. The US students may well be perceived as using up an unequal share of available resources. Their presence in classes may well be a mixed blessing at best. Their tendency to function in a liberal learning mode (thus, to challenge the professor in class situations) may well be seen, in an African context for example, as inappropriate and disturbing.

It is also useful to explore in a little more detail the question of financial benefit to the host university. While the fees paid to universities will certainly have a positive impact, it is also clear the income is subject to a volatile environment. The study abroad market is not a stable one but subject to many vagaries. Host universities may well be forced to invest in human and physical resources while the income generated is subject to too many variables for it to be considered a stable source of funding. A demand for increased programs should certainly be accompanied by a demand for investment from the US universities in the infrastructures that they need to manage and develop programs to the standards expected by US study abroad students.

This is closely related to the question of "capacity building":

In its most general sense, "capacity building" refers to a process by which members of a community become enabled to oversee necessary functions of management or governance, as well as to provide particular services in a sustainable or long-term manner. ..."Capacity building" must also promote equitable access to key resources relevant to participants in a given program or project, as well as address the power relationships between and among the people and institutions involved. ${ }^{15}$

These are key factors in the development of education abroad in non-traditional locations and they are barely addressed in the current wave of enthusiasm for development. The power relationships (based on inequitable wealth) are in particular a significant barrier to communication and immersion.

\section{The Immersion Issue}

At least one function of study abroad has to be to expose students to the culture in which they have chosen to study and to enable them to interact with local people in a way that maximises the possibility of genuine communication. 
In any context, there will be barriers to that process such as language, duration of stay, learning styles, cultural sensitivity and so on. In non-traditional locations there are other very significant issues that establish barriers: privilege and wealth. Hudson gives a coherent example of how these factors impacted on communication between US and local students in Africa:

The dollar exchange rate is so strong throughout Africa, that all American students are considerably wealthier than their local peers. International students are in Africa for a limited time. They want to eat out, travel at weekends and experience as much of their host country as possible. Local students cannot afford that. In their shared accommodation in the evenings, American students will type up their assignments on their laptops (if they have electricity), while most African students will hand-write theirs. Is this a mutually beneficial cultural exchange? How would we feel if the roles were reversed? ${ }^{16}$

Inevitably local students are unable to participate in the life that US students take for granted. They may well feel like poor relations (which, indeed, they are).

\section{C o n c I us ion}

The case for US study abroad is a crucial one and needs to be tied closely to academic credibility. We are already burdened by assumptions that are framed in relatively broad and inexact terms: global competence, cross-cultural communication, enhancing mutual understanding, personal growth, etc. etc. There is a challenge to go beyond definitions that are based on concepts that are vaguely humanitarian and vaguely idealistic. That liberal mix threatens to sag beneath the weight of starry-eyed idealism when the "benefits" of study in the developing world are articulated in terms of the attraction of the exotic.

On the other hand, there are also clear dangers in articulating an educational policy in terms of its benefits to US national security. There is a more coherent rationale implicit in this position but it is also an unpalatable one if we believe in the educational value of contact across cultures. To frame the benefits of education abroad only in terms of US political interest is to distort a core objective which has to be based on an assumption that contact is of mutual benefit to both participants and hosts. The education abroad community is profoundly weakened if it permits itself to be seen as a tool for US foreign policy. The objectives of the whole enterprise have to be constructed emphatically in educational terms. 
There is also no widespread evidence to suggest that the clamor for expansion of study abroad in non-traditional locations is driven by increased interest on US campuses in the study of those regions. The example of African Studies or Indian Studies signifies that there has been no major growth of interest in those areas that would suggest that current demand significantly exceeds current supply. In short, non-traditionalism is not driven by real academic need; it is driven by an unholy trinity of national political interest, the pursuit of the exotic and a missionary tendency.

There are real and creditable reasons for wanting to expand education abroad beyond the traditional locations but these are not articulated in the current orthodoxy where the interests of the hosts and of the US students are incidental to the pursuit of the exotic. The growth of programs in the developing world should be driven by a combination of curriculum development on US campuses with an investment in building infrastructure in universities in those regions. This would create an academic rationale for the expansion and a development that serves the mutual interest of higher education across the world. If we want to be taken seriously, we have to start thinking seriously.

\section{Notes}

${ }^{1}$ Global Competence and National Needs: One Million Americans Studying Abroad, Commission on the Abraham Lincoln Study Abroad Fellowship Program, November 2005, p.12.

${ }^{2}$ Goals of the Lincoln Commission, http://www.lincolncommission.org/ commissioners.html

${ }^{3}$ http://nsep.aed.org/faq

${ }_{4}^{4}$ It would unfair and unreasonable to cite these sources. I do not intend to offer these as criticisms of any organization or university but rather as a symptom of a malaise that is widespread in the field.

${ }^{5}$ I am indebted to Yan Yan Leung at FIE and Dr Geoffrey Williams of Africa House, New York University for the time they freely gave to research abundant statistics for this article.

Further information on African languages may be found at : http://elctl. msu.edu/summaries/africa/

${ }^{6}$ Another valuable source of information on Area Studies is the Digest of Education Statistics: http://nces.ed.gov/programs/digest/

National Council of Less Commonly Taught Languages: http://www. councilnet.org/index.html 
${ }^{7}$ The source of these figures and further statistical information can be found in Elizabeth Welles, "Foreign Language Enrollments in United States Institutions of Higher Education, Fall 2002," Association of Foreign Languages, ADF Bulletin, v. 35, nos 2-3, Winter-Spring, 2004, pp.7-24.

${ }^{8}$ http://nsep.aed.org/boren

${ }^{9}$ Global Competence and National Needs: One Million Americans Studying Abroad, Commission on the Abraham Lincoln Study Abroad Fellowship Program, November 2005, p.vi.

${ }^{10}$ Study abroad in China increased by a dramatic $90 \%$ (4,737, up from 2,493 in 2002/03), making China the 9th-leading host destination for American students, up from \#12 the previous year, while the number of students going to India increased by $65 \%$ to 1,157 . The United Kingdom continues to be the leading destination for U.S. students (32,237, up 2\%) followed by Italy, with a very strong increase of $16 \%$, to 21,922 . The remaining "top ten" host destinations saw increases in the range of 5 to $7 \%$ : Spain (20,080, up 6\%), France $(13,718$, up 5\%), Australia (11,418, up 7\%), Mexico (9,293, up 6\%), Germany (5,985, up 7\%), Ireland (5,198, up 6\%) and Costa Rica (4,510, up 5\%), with the exception of China's 90\% increase, described above. Open Doors, November 2006, http://opendoors.iienetwork.org/?p=69735

${ }^{11}$ Christine Hudson, "The Impact of Study Abroad on Host Communities" Paper presented at the Council on International Educational Exchange,54th International Conference, Portland, Oregon, November, 2001.

${ }^{12} \mathrm{Ibid}$

${ }^{13}$ Global Competence and National Needs: One Million Americans Studying Abroad, Commission on the Abraham Lincoln Study Abroad Fellowship Program, November 2005, pp.ix-x.

${ }^{14}$ However modestly, the UK government has at least recognised that development needs to have a mutual dimension: "Africa's universities are at the heart of Africa's future. They are key to Africa's economic growth. As the Commission for Africa report recommended, we need to help support their development and particularly to strengthen centres of research, science and technology. We want to ensure that the expertise we have in the UK can be used to help revitalise African higher education and at the same time, enrich our own understanding of African issues. There are many ways in which the relationships developed through collaboration will benefit UK universities and the increasingly diverse learning environment in which they operate." Bill Rammell, UK Higher Education Minister, Tuesday November 29th, 2005, The Education Guardian, http://education. guardian.co.uk/higher/worldwide/story/0,9959,1653427,00.html 
${ }^{15}$ Jennifer E. Coffman and Kevin Brennan, "African Studies Abroad: Meaning and Impact of America’s Burgeoning Export Industry," Frontiers: The Interdisciplinary Journal of Study Abroad, v.9., Fall, 2003, p.142. ${ }^{16} \mathrm{Ibid}$ 